\title{
Prognostic value of ephrin B receptors in breast cancer: An online survival analysis using the microarray data of 3,554 patients
}

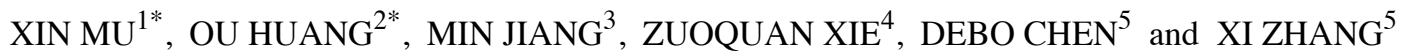 \\ ${ }^{1}$ Department of Urology, The Second Affiliated Hospital of Fujian Medical University, Quanzhou, Fujian 362000; \\ ${ }^{2}$ Comprehensive Breast Health Center, Ruijin Hospital, Shanghai Jiaotong University School of Medicine, Shanghai 200025; \\ ${ }^{3}$ Department of Oncology, The First Affiliated Hospital of Soochow University, Suzhou, Jiangsu 215000; \\ ${ }^{4}$ Division of Anti-tumor Pharmacology, State Key Laboratory of Drug Research, Shanghai Institute of Materia Medica, \\ Chinese Academy of Sciences, Shanghai 200025; ${ }^{5}$ Department of Breast Oncology, The First Hospital of \\ Quanzhou Affiliated to Fujian Medical University, Quanzhou, Fujian 362000, P.R. China
}

Received April 29, 2018; Accepted April 17, 2019

DOI: $10.3892 / 01.2019 .10363$

\begin{abstract}
The roles of Ephrin B (EphB) receptors in cancer are relatively unknown as these receptors are associated with complex signaling pathways. A limited number of studies have investigated the association between EphB receptors and prognosis. Using the Kaplan-Meier plotter database, the present study investigated the associations between the mRNA expression levels of five EphB receptors and the outcomes of 3,554 patients with breast cancer who had been followed-up for 20 years. Hazard ratios (HR) and 95\% confidence intervals (CI) were calculated to assess the relative risk of survival. The results demonstrated that high mRNA expression levels of EphB2 (HR, 0.74; 95\% CI, 0.66-0.84; P=2.1x10-6), EphB4 (HR, 0.82; 95\% CI, 0.72-0.93; $\mathrm{P}=0.0023$ ) and EphB6 (HR, 0.69; 95\% CI, 0.61-0.78; $\left.\mathrm{P}=3 \times 10^{-9}\right)$ were significantly associated with improved survival, while a high mRNA expression level of EphB3 (HR, 1.14; 95\% CI, 1.01-1.28; P=0.029) was associated with worse survival for patients with breast cancer. High expression levels of all EphB receptors, including EphB1 (HR, 1.4; 95\% CI, 1.02-1.94; P=0.039), EphB2 (HR, 1.34; 95\% CI, 1.07-1.67; P=0.011), EphB3 (HR, 1.39; 95\% CI, 1.11-1.73, P=0.0038), EphB4 (HR, 1.33; 95\% CI, 1.06-1.67;
\end{abstract}

Correspondence to: Dr Xi Zhang, Department of Breast Oncology, The First Hospital of Quanzhou Affiliated to Fujian Medical University, Anji Road, Quanzhou, Fujian 362000, P.R. China

E-mail: hee_rainday@foxmail.com

${ }^{*}$ Contributed equally

Abbreviations: EphB, ephrin B; HR, hazard ratio; BC, breast cancer; KM plotter, Kaplan-Meier plotter; RFS, relapse-free survival; TKR, tyrosine kinase receptor; CI, confidence interval; ER, estrogen receptor; PgR, progesterone receptor; HER2, human epidermal receptor 2

Key words: breast cancer, ephrin B receptors, prognosis, Kaplan-Meier plotter, hazard ratio
$\mathrm{P}=0.013)$ and EphB6 (HR, 1.32; 95\% CI, 1.05-1.65; $\mathrm{P}=0.016)$, were associated with an increased risk of mortality in patients with lymph-node-positive breast cancer. High mRNA expression levels of EphB1 were not associated with survival for all patients with breast cancer (HR, 0.85; 95\% CI, 0.72-1.01; $\mathrm{P}=0.058$ ). The results of the present suggested that EphB receptors may be useful as prognostic biomarkers of breast cancer.

\section{Introduction}

According to the American Cancer Society (ACS), breast cancer (BC) is the most common malignancy and the second most common cause of cancer-associated mortality, in the USA (1). The ACS have estimated a total of 268,670 newly diagnosed cases of invasive BC and 41,400 BC-associated mortalities among females in the USA in 2018 (1). Current treatments, including surgery, endocrine therapy, chemotherapy and radiation, have greatly improved the survival of females diagnosed with BC (2); however, a cure remains to be identified. Understanding the underlying mechanisms that contribute to the progression of this disease is important for developing novel targets.

The Ephrin (Eph) family is the largest family of tyrosine kinase receptors (TKRs). Eph proteins are subdivided into two categories, $\mathrm{A}$ and $\mathrm{B}$, according to their sequence homology and affinity for corresponding transmembrane ephrin ligands $(3,4)$. EphB TKRs are considered as candidates for novel anticancer therapies due to their participation in both physiological and pathological processes (5-7). It has been reported that metastatic BC cell motility may be dynamically guided by the crosstalk between epidermal growth factor-mediated chemotaxis and contact inhibition of locomotion, mediated in part by EphB receptors (8). This suggests that EphB receptors may serve a role in the recurrence of human $\mathrm{BC}$ (8). Other preclinical and laboratory studies have also revealed the function of EphB TKRs in tumor growth, invasion, metastasis and angiogenesis (9), including in $\mathrm{BC}(10)$. In the human genome there are five distinct EphB receptors, which aberrantly bind three 
membrane-anchored ephrin-B ligands (11-13). This aberrant interaction between ligands and receptors results in pleiotropic functions and bidirectional signaling, which makes the role of EphB receptors in cancer complex (9). Additionally, the activities of EphB receptors in cancer remain controversial, with evidence supporting both tumor-promoting and tumor-inhibiting functions (9). Nevertheless, EphB receptors are promising candidates for novel therapeutic targets in cancer.

The present study aimed to resolve this controversy by comprehensively investigating the prognostic roles of EphB receptors in BC, including EphB1, EphB2, EphB3, EphB4 and EphB6, using a large population-based database. The Kaplan-Meier plotter (KM plotter) database (14-18) was used to calculate the relapse-free survival (RFS) from a total of 3,554 patients with $\mathrm{BC}$ and the mRNA-level data of EphB receptors were downloaded. Relapse-free survival was defined as the time from diagnosis to the first relapse or death as a result of any cause. The analyses performed revealed significant associations between EphB receptors and human $\mathrm{BC}$ progression, which, to the best of our knowledge, have not been previously investigated in $\mathrm{BC}$.

\section{Materials and methods}

An online database was used to determine the association between EphB mRNA expression and RFS. At present, the database contains data regarding lung (14), ovarian (19), gastric and breast malignancies (18). The database was first set up from the Gene Expression Omnibus (GEO) database (www.ncbi.nlm.nih.gov/geo/). The gene expression data and survival information of 3,554 patients with BC, with 20 years of follow-up, were obtained for the current study, the dataset of which was originally from Affymetrix HG-U133A (GPL96) and HG-U133 Plus 2.0 (GPL570) microarrays that have 22,277 probe sets in common (18). Briefly, survival information and mRNA levels of five individual EphB receptors, including EphB1, EphB2, EphB3, EphB4 and EphB6, were downloaded from the KM plotter database (http://kmplot.com/analysis/index. php? $\mathrm{p}=$ service \&cancer=breast, 2018 edition) to provide KM plots. All patients with RFS available were included. The JetSet best probe sets were selected. The hazard ratio (HR), number-at-risk and $95 \%$ confidence intervals (CI) were displayed on the plot. All percentiles were computed and the highest performing threshold was selected as a cut-off. Specifically, patients were split based on the 'auto select best cut-off', and all possible cut-off values between the lower and upper quartiles were computed, and the best performing threshold was used as a cut-off. A log-rank test was used to calculate $\mathrm{P}$-values. $\mathrm{P}<0.05$ was considered to indicate statistically significance.

To further evaluate the association between EphB gene expression and tumor relapse in patients with $\mathrm{BC}$, the expression of selected genes was determined in patients stratified by estrogen receptor (ER), progesterone receptor (PgR), human epidermal growth factor receptor 2 (HER2), lymph node status, pathological grade and molecular subtype. In addition, the cut-off was set by the best performing threshold after all percentiles were computed.

\section{Results}

Associations between mRNA expression levels of EphB receptors and RFS. Firstly, the impact of EphB1 mRNA expression on the prognosis of 1,660 patients with $\mathrm{BC}$ was evaluated using the KM plotter database. A survival curve was generated using the Affymetrix ID: 230425_at EPHB1 (Fig. 1A). A significant association was not identified between the RFS and high mRNA expression of EphB1 for all patients with $\mathrm{BC}$ followed up for 20 years (HR, 0.85; CI, 0.72-1.01; $\mathrm{P}=0.058$ ). Subsequently, the impact of EphB2 mRNA expression on the prognosis of 3,554 patients was analyzed. High mRNA expression of EphB2 was associated with improved RFS (HR, 0.74; CI, 0.66-0.84; $\mathrm{P}=2.1 \times 10^{-6}$; Affymetrix ID: 209588_at EPHB2; Fig. 1B). The prognostic effect of EphB3 mRNA expression in 3,554 patients with BC (Affymetrix ID: 204600_at EPHB3) is presented in Fig. 1C. In contrast to EphB2, high mRNA expression of EphB3 was associated with worse RFS. The prognostic effect of EphB4 mRNA expression was then analyzed. High expression of EphB4 mRNA was positively associated with RFS in 3,554 patients with BC (Affymetrix ID: 202894_at EPHB4; Fig. 1D). Finally, the impact of EphB6 mRNA expression on the prognosis of 3,554 patients with BC was investigated. High EphB6 mRNA expression was positively associated with RFS (Affymetrix ID: 204718_at EPHB6; Fig. 1E).

Association between EphB receptors with the clinicopathological features of patients with $B C$. The present study further determined the association between EphB receptors with clinicopathological features, including ER status (Table I), PgR status (Table II), HER2 status (Table III), lymph node status (Table IV) and pathological grade (Table V) of patients with BC. It should be noted that information on ER, PgR, HER2, lymph node status and pathological grade was not available for all 3,554 patients.

EphB1 expression data and ER status were available for a total of 1,008 patients, and both ER status and EphB2, B3, B4 or B6 expression data were available for 2,473 patients. For ER-positive patients, it was demonstrated that EphB1 was positively associated with RFS (HR, 0.67; CI, 0.45-0.99, P=0.044); however, EphB3 was negatively associated with RFS (HR, 1.31; CI, 1.09-1.56; $\mathrm{P}=0.0029)$. By contrast, in ER-negative subgroups, EphB1 (HR, 0.56; CI, 0.36-0.86; P=0.0081), EphB3 (HR, 0.76; CI, 0.59-0.98; P=0.035) and EphB6 (HR, 0.72 ; CI, 0.55-0.93; $\mathrm{P}=0.012$ ) were identified to be associated with improved RFS.

As demonstrated in Table II, both EphB1 expression and $\mathrm{PgR}$ status data were available for 861 patients, and $\mathrm{PgR}$ status and EphB2, EphB3, EphB4 or EphB6 expression data were available for 1,008 patients. Only EphB1 was associated with improved RFS in PgR-negative patients (HR, 0.6; CI, 0.4-0.91; $\mathrm{P}=0.014$ ). However, EphB2 (HR, 1.66; CI, 1.22-2.26; $\mathrm{P}=0.0012)$ and EphB4 (HR, 1.51; CI, 1.1-2.08; $\mathrm{P}=0.0098)$ expression were revealed to be associated with worse RFS in PgR-negative subgroups.

As presented in Table III, both EphB1 expression and HER2 status data were available for 785 patients, and HER2 status and EphB2, EphB3, EphB4 or EphB6 expression data were available for 924 patients. In HER2-positive patients, EphB2 (HR, 
Table I. Association of EphB receptors with ER status in patients with breast cancer.

\begin{tabular}{llcll}
\hline EphB receptor & ER status & Cases $(\mathrm{n})$ & HR $(95 \%$ CI $)$ & P-value \\
\hline B1 & Positive & 695 & $0.67(0.45-0.99)$ & $0.044^{\mathrm{a}}$ \\
& Negative & 313 & $0.56(0.36-0.86)$ & $0.008^{\mathrm{a}}$ \\
B2 & Positive & 1,802 & $1.16(0.97-1.39)$ & 0.110 \\
& Negative & 671 & $0.78(0.60-1.02)$ & 0.070 \\
B3 & Positive & 1,802 & $1.31(1.09-1.56)$ & $0.003^{\mathrm{a}}$ \\
& Negative & 671 & $0.76(0.59-0.98)$ & $0.035^{\mathrm{a}}$ \\
B4 & Positive & 1,802 & $1.21(0.93-1.10)$ & 0.160 \\
& Negative & 671 & $0.85(0.71-1.02)$ & 0.085 \\
B6 & Positive & 1,802 & $0.72(0.55-0.93)$
\end{tabular}

${ }^{\mathrm{a}} \mathrm{P}<0.05$. EphB, ephrin B; ER, estrogen receptor; HR, hazard ratio; CI, confidence interval.
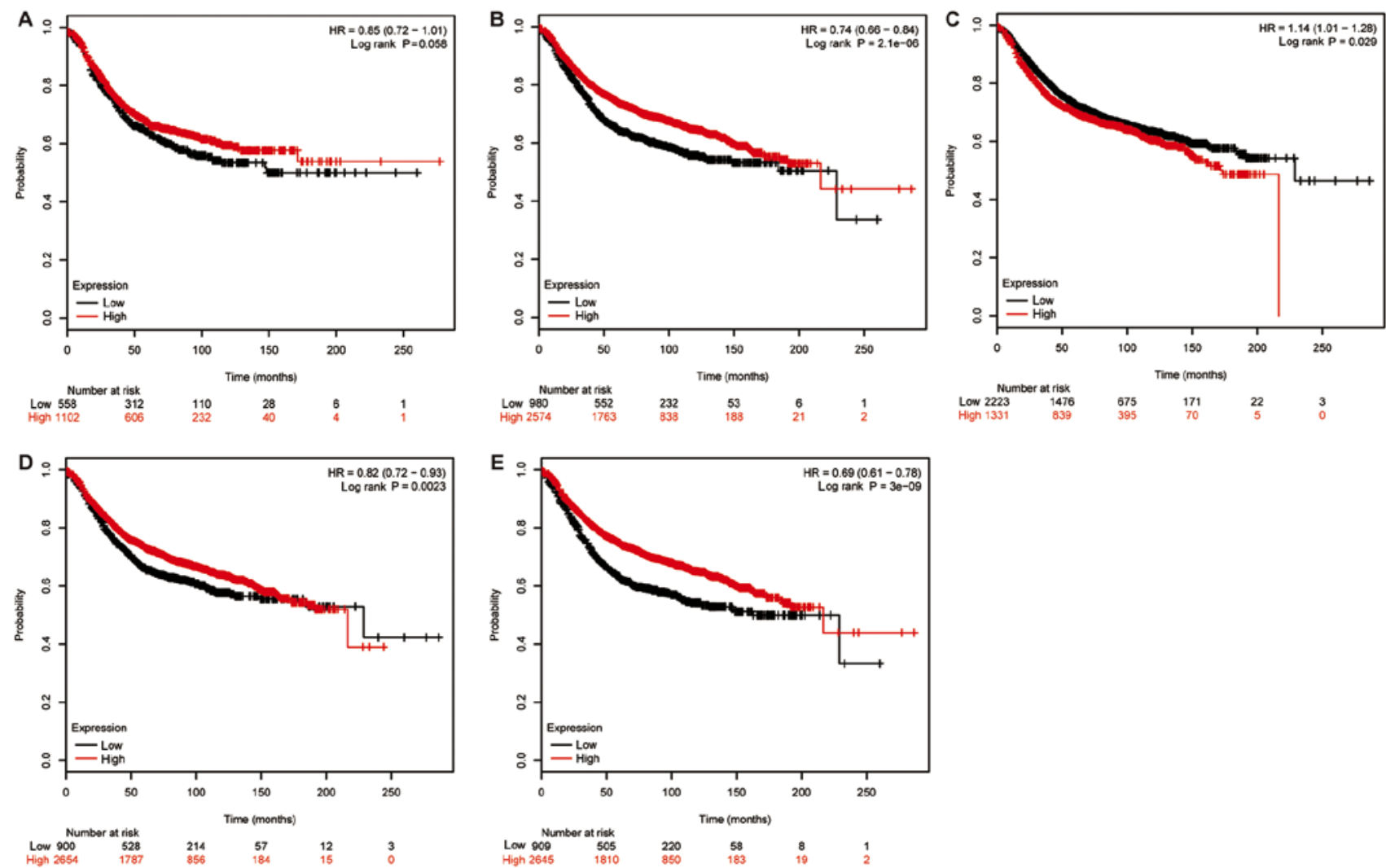

Figure 1. Prognostic effect of EPHB receptor expression. Kaplan-Meier plots of relapse-free survival for patients with breast cancer were presented. The HR, 95\% confidence intervals, P-values and numbers at risk are displayed on the plots. The Affymetrix IDs included (A) 230425_at (EPHB1), (B) 209588_at (EPHB2), (C) 204600_at (EPHB3), (D) 202894_at (EPHB4) and (E) 204718_at (EPHB6). HR, hazard ratio; EPHB, ephrin B.

2.03; CI, 1.09-3.77; P=0.023), EphB4 (HR, 1.95; CI, 1.12-3.42; $\mathrm{P}=0.017)$ and EphB6 (HR, 2.19; CI, 1.07-4.47; P=0.028) were negatively associated with RFS. In HER2-negative patients with BC, EphB2 (HR, 1.52; CI, 1.15-2.02; P=0.0033) and EphB3 (HR, 1.4; CI, 1.05-1.86; $\mathrm{P}=0.019)$ were identified to be associated with worse RFS.

As demonstrated in Table IV, both EphB1 expression and lymph node status data were available for 1,116 patients, and lymph node status and EphB2, EphB3, EphB4 or EphB6 expression data were available for 2,758 patients. EphB1, EphB2, EphB3, EphB4 and EphB6 were all negatively associated with RFS in lymph-node-positive patients with BC. EphB3 (HR, 1.36; CI, 1.13-1.65; P=0.0014) and EphB4 (HR, 1.21; CI, 1.01-1.43; $\mathrm{P}=0.034)$ were revealed to be associated with worse RFS in lymph-node negative patients.

As presented in Table V, both EphB1 expression and pathological grade data were available for 675 patients, and pathological grade and EphB2, EphB3, EphB4 or EphB6 expression data were 
Table II. Association of EphB receptors with PgR status in patients with breast cancer.

\begin{tabular}{|c|c|c|c|c|}
\hline EphB receptor & PgR status & Cases (n) & $\mathrm{HR}(95 \% \mathrm{CI})$ & P-value \\
\hline \multirow[t]{2}{*}{ B1 } & Positive & 489 & $0.84(0.56-1.25)$ & 0.380 \\
\hline & Negative & 372 & $0.60(0.40-0.91)$ & $0.014^{\mathrm{a}}$ \\
\hline \multirow[t]{2}{*}{ B2 } & Positive & 525 & $1.31(0.86-1.98)$ & 0.200 \\
\hline & Negative & 483 & $1.66(1.22-2.26)$ & $0.001^{\mathrm{a}}$ \\
\hline \multirow[t]{2}{*}{ B3 } & Positive & 525 & $0.80(0.54-1.20)$ & 0.280 \\
\hline & Negative & 483 & $1.38(0.98-1.94)$ & 0.067 \\
\hline \multirow[t]{2}{*}{ B4 } & Positive & 525 & $1.41(0.98-2.03)$ & 0.059 \\
\hline & Negative & 483 & $1.51(1.10-2.08)$ & $0.010^{\mathrm{a}}$ \\
\hline \multirow[t]{2}{*}{ B6 } & Positive & 525 & $1.41(0.94-2.10)$ & 0.093 \\
\hline & Negative & 483 & $1.21(0.88-1.66)$ & 0.250 \\
\hline
\end{tabular}

${ }^{\mathrm{a}} \mathrm{P}<0.05$. EphB, ephrin B; PgR, progesterone receptor; HR, hazard ratio; CI, confidence interval.

Table III. Association of EphB receptors with HER2 status in patients with breast cancer.

\begin{tabular}{llccc}
\hline EphB receptor & HER2 status & Cases (n) & HR (95\% CI) & P-value \\
\hline B1 & Positive & 150 & $0.59(0.30-1.17)$ & 0.130 \\
& Negative & 635 & $1.27(0.94-1.71)$ & 0.110 \\
B2 & Positive & 168 & $2.03(1.09-3.77)$ & $0.023^{\text {a }}$ \\
& Negative & 756 & $1.52(1.15-2.02)$ & $0.003^{\text {a }}$ \\
B3 & Positive & 168 & $1.43(0.83-2.45)$ & 0.190 \\
& Negative & 756 & $1.40(1.05-1.86)$ & $0.019^{\text {a }}$ \\
B4 & Positive & 168 & $1.95(1.12-3.42)$ & $0.017^{\text {a }}$ \\
& Negative & 756 & $1.29(0.99-1.68)$ & 0.057 \\
B6 & Positive & 168 & $2.19(1.07-4.47)$ & $0.028^{\text {a }}$ \\
& Negative & 756 & $1.33(1.00-1.77)$ & 0.052
\end{tabular}

${ }^{a} \mathrm{P}<0.05$. EphB, ephrin B; HER2, human epidermal receptor 2; HR, hazard ratio; CI, confidence interval.

Table IV. Association of EphB receptors with lymph node status in patients with breast cancer.

\begin{tabular}{|c|c|c|c|c|}
\hline EphB receptor & Lymph node status & Cases (n) & HR (95\% CI) & P-value \\
\hline \multirow[t]{2}{*}{ B1 } & Positive & 665 & $1.40(1.02-1.94)$ & $0.039^{\mathrm{a}}$ \\
\hline & Negative & 451 & $0.73(0.43-1.24)$ & 0.250 \\
\hline \multirow[t]{2}{*}{ B2 } & Positive & 945 & $1.34(1.07-1.67)$ & $0.011^{\mathrm{a}}$ \\
\hline & Negative & 1,813 & $1.16(0.95-1.43)$ & 0.150 \\
\hline \multirow[t]{2}{*}{ B3 } & Positive & 945 & $1.39(1.11-1.73)$ & $0.004^{\mathrm{a}}$ \\
\hline & Negative & 1,813 & $1.36(1.13-1.65)$ & $0.001^{\mathrm{a}}$ \\
\hline \multirow[t]{2}{*}{ B4 } & Positive & 945 & $1.33(1.06-1.67)$ & $0.013^{\mathrm{a}}$ \\
\hline & Negative & 1,813 & $1.21(1.01-1.43)$ & $0.034^{\mathrm{a}}$ \\
\hline \multirow[t]{2}{*}{ B6 } & Positive & 945 & $1.32(1.05-1.65)$ & $0.016^{\mathrm{a}}$ \\
\hline & Negative & 1,813 & $0.85(0.69-1.05)$ & 0.130 \\
\hline
\end{tabular}

${ }^{\mathrm{a}} \mathrm{P}<0.05$. EphB, ephrin $\mathrm{B} ; \mathrm{HR}$, hazard ratio; $\mathrm{CI}$, confidence interval.

available for 1,755 patients. EphB1 was demonstrated to be positively associated with RFS in patients with grade I BC (HR, 0.31;
CI, 0.09-1.05; $\mathrm{P}=0.046)$. EphB2 was identified to be negatively associated with RFS in patients with grade III BC (HR, 1.29; 
Table V. Association of EphB receptors with pathological grades of patients with breast cancer.

\begin{tabular}{lllll}
\hline EphB receptors & Grade & Cases (n) & HR $(95 \%$ CI $)$ & P-value \\
\hline B1 & I & 97 & $0.31(0.09-1.05)$ & $0.046^{\mathrm{a}}$ \\
& II & 187 & $1.40(0.78-2.49)$ & 0.250 \\
B2 & III & 391 & $0.73(0.48-1.11)$ & 0.140 \\
& I & 308 & $1.70(0.98-2.95)$ & 0.057 \\
& II & 724 & $1.29(0.95-1.76)$ & 0.110 \\
B3 & III & 723 & $1.29(1.00-1.65)$ & $0.046^{\mathrm{a}}$ \\
& I & 308 & $1.39(1.06-1.82)$ & 0.230 \\
B4 & II & 724 & $1.22(0.94-1.57)$ & $0.015^{\mathrm{a}}$ \\
& III & 723 & $1.99(0.99-3.99)$ & 0.130 \\
B6 & I & 308 & $1.16(0.9-1.51)$ & $0.048^{\mathrm{a}}$ \\
& II & 724 & $0.31(1.02-1.68)$ \\
& III & 723 & $0.77(0.59-0.99)$ \\
\end{tabular}

${ }^{\mathrm{a}} \mathrm{P}<0.05$. EphB, ephrin B; HR, hazard ratio; CI, confidence interval.

Table VI. Associations of EphB receptors with molecular subtypes of patients with breast cancer.

\begin{tabular}{|c|c|c|c|c|}
\hline EphB receptor & Molecular subtype & Cases (n) & HR $(95 \%$ CI $)$ & P-value \\
\hline \multirow[t]{4}{*}{ B1 } & Basal & 339 & $0.75(0.52-1.08)$ & 0.120 \\
\hline & Luminal A & 783 & $0.81(0.62-1.05)$ & 0.110 \\
\hline & Luminal B & 389 & $0.57(0.38-0.86)$ & $0.007^{\mathrm{a}}$ \\
\hline & HER2+ & 149 & $0.58(0.35-0.95)$ & $0.029^{\mathrm{a}}$ \\
\hline \multirow[t]{4}{*}{ B2 } & Basal & 580 & $0.69(0.53-0.89)$ & $0.005^{\mathrm{a}}$ \\
\hline & Luminal A & 1,764 & $0.70(0.59-0.84)$ & $<0.001^{\mathrm{a}}$ \\
\hline & Luminal B & 1,002 & $0.71(0.56-0.89)$ & $0.003^{\mathrm{a}}$ \\
\hline & HER2+ & 208 & $0.5(0.33-0.78)$ & $0.002^{\mathrm{a}}$ \\
\hline \multirow[t]{4}{*}{ B3 } & Basal & 580 & $0.74(0.57-0.97)$ & $0.025^{\mathrm{a}}$ \\
\hline & Luminal A & 1,764 & $0.89(0.73-1.08)$ & 0.230 \\
\hline & Luminal B & 1,002 & $1.13(0.92-1.39)$ & 0.240 \\
\hline & HER2+ & 208 & $2.00(1.21-3.28)$ & $0.006^{\mathrm{a}}$ \\
\hline \multirow[t]{4}{*}{ B4 } & Basal & 580 & $0.86(0.66-1.12)$ & 0.260 \\
\hline & Luminal A & 1,764 & $0.64(0.53-0.77)$ & $<0.001^{\mathrm{a}}$ \\
\hline & Luminal B & 1,002 & $0.85(0.69-1.03)$ & 0.100 \\
\hline & HER2+ & 208 & $1.36(0.85-2.18)$ & 0.190 \\
\hline \multirow[t]{4}{*}{ B6 } & Basal & 580 & $0.70(0.52-0.93)$ & $0.015^{\mathrm{a}}$ \\
\hline & Luminal A & 1,764 & $0.61(0.51-0.72)$ & $<0.001^{\mathrm{a}}$ \\
\hline & Luminal B & 1,002 & $0.62(0.48-0.80)$ & $<0.001^{\mathrm{a}}$ \\
\hline & HER2+ & 208 & $0.50(0.30-0.84)$ & $0.008^{\mathrm{a}}$ \\
\hline
\end{tabular}

${ }^{a} \mathrm{P}<0.05$. EphB, ephrin B; HER2, human epidermal receptor 2; HR, hazard ratio; CI, confidence interval.

CI, 1-1.65; $\mathrm{P}=0.046)$. EphB3 was revealed to be associated with worse RFS in patients with grade II BC (HR, 1.39; CI, 1.06-1.82; $\mathrm{P}=0.015)$. EphB4 was identified to be associated with worse RFS in patients with both grade I BC (HR, 1.99; CI, 0.99-3.99; $\mathrm{P}=0.048)$ and grade III BC (HR, 1.31; CI, 1.02-1.68; $\mathrm{P}=0.034)$.
EphB6 was revealed to be negatively associated with RFS in patients with grade II BC (HR, 0.77; CI, 0.59-0.99; $\mathrm{P}=0.044)$.

Associations of EphB receptors with molecular subtypes of $B C$. BC can be classified into four distinct molecular subtypes, 
including basal-like, luminal-A, luminal-B and HER2-positive. As presented in Table VI, EphB1 was revealed to be associated with improved RFS in patients with luminal-B (HR, 0.57; CI, 0.38-0.86; $\mathrm{P}=0.0072)$ and HER2-positive $\mathrm{BC}(\mathrm{HR}, 0.58$; $\mathrm{CI}$, 0.35-0.95; $\mathrm{P}=0.029)$. EphB2 and EphB6 were identified to be positively associated with RFS in each molecular subgroup. EphB3 was revealed to be associated with improved RFS in patients with basal-like BC (HR, 0.74; CI, 0.57-0.97; P=0.025); however, it was associated with worse RFS in patients with HER2-positive BC (HR, 2.0; CI, 1.21-3.28; P=0.0055). EphB4 was identified to be positively associated with RFS in patients with luminal-A BC (HR, 0.64; CI, 0.53-0.77; $\left.\mathrm{P}=1.9 \times 10^{-6}\right)$.

\section{Discussion}

The KM plotter database was generated from the GEO database. The expression data of 22,277 genes were initially available for 1,809 patients with BC (18). Gene expression data and survival information have since been validated and updated for 3,554 patients with BC. Therefore, the $\mathrm{KM}$ plotter can be used to analyze the prognostic effect of individual genes with clinical outcomes, including overall survival (OS) and RFS (http://kmplot.com/analysis/index. php? $=$ service \&cancer=breast). As certain patients lacked OS data, the current study focused on RFS. The present study comprehensively and specifically analyzed the associations between the expression levels of EphB receptors, including EphB1, EphB2, EphB3, EphB4 and EphB6, and RFS in all patients with $\mathrm{BC}$, as well as in subgroups according to clinicopathological features, which, to the best of our knowledge, has not previously been reported. EphA receptors were not discussed in the present study and may be investigated in future studies. EphB receptors predominantly function independently on class B ephrin ligands in BC, therefore, the current study only analyzed and discussed EphB receptors $(6,9)$.

A limited number of studies have investigated EphB1 in patients with BC. A BC-risk, genome-wide association study suggested an association between carcinogenesis and germline-somatic rs3732568 in EphB1 (20). The current study revealed that EphB1 was not associated with RFS. In subgroup analysis, EphB1 was positively associated with RFS in patients with PgR-negative and grade I BC. Previous studies have demonstrated that active EphB1 can activate the mitogen-activated protein kinase (MAPK)/extracellular signal-regulated kinase (ERK), c-Jun and integrin signaling pathways (21-23).

EphB2 has more widely been investigated in previous studies. It has been demonstrated that EphB2 can regulate apoptosis, autophagy and invasion in human BC cells $(24,25)$. One previous study examined the expression of EphB2 protein by immunohistochemistry. This study revealed that associations with clinical outcomes were the opposite for membranous and cytoplasmic EphB2. Membranous EphB2 protein was associated with improved $\mathrm{BC}$ prognosis, whereas cytoplasmic EphB2 protein predicted a worse BC prognosis (26). EphB2 has also been validated to exhibit a novel transforming growth factor- $\beta$ (TGF- $\beta$ ) targeting TGF- $\beta 3$-mediated invasion and migration in $\mathrm{BC}$ (27). The present study identified that high mRNA expression of EphB2 predicted a longer RFS in all patients with $\mathrm{BC}$, whereas it was associated with worse RFS in PgR-negative and grade III subgroups. Similar to EphB1, EphB2 can also stimulate the MAPK/ERK pathway, which leads to improved responsiveness to EphB stimulation in a positive feedback loop (28). However, in a different context, EphB2 can inhibit the oncogenic ERK signaling pathway, which in turn suppresses its activation by ephrins (29).

To the best of our knowledge, the role of EphB3 in BC is largely unknown. The current study revealed that high mRNA expression of EphB3 was associated with a longer RFS in all patients with BC. In subgroup analysis, EphB3 was identified to indicate a shorter RFS in patients with ER-positive, HER2-negative and grade II BC, but an improved RFS for patients with ER-negative BC. It has been demonstrated that EphB3 receptor can inhibit cell adhesion and migration in a kinase-dependent/independent manner (30). However, in malignant lymphocytes it exhibits the opposite effect by activating the Akt pathway and suppressing the apoptosis pathway (31).

EphB4 is involved in regulating mammary gland development. EphB4 protein overexpression has been revealed to induce delayed development of the mammary gland during puberty and pregnancy $(32,33)$. In addition, EphB4 knockdown has been demonstrated to inhibit the survival, migration and invasion of BC cells (34). Furthermore, EphB4 has been identified to promote erythropoietin-induced tumor growth in human BC (35). In one small-sample study, patients with HER2-positive BC with EphB4 and EphB2 overexpression were associated with a shorter survival time (36). However, to the best of our knowledge, high expression of EphB4 alone remains to be identified as an independent prognostic factor. On the contrary, another study revealed negative associations between EphB4 and clinical outcomes by investigating protein expression in breast tissue microarrays (37). Notably, dual functions of this receptor in tumor promotion and inhibition have been reported on the basis of its ligand presence or absence $(9,38)$. Previous studies have been based on small samples. In the present large analysis it was identified that EphB4 mRNA levels could predict improved RFS in all patients with BC, while it was associated with worse RFS in PgR-negative, HER2-positive, grade I and grade III subgroups, which supports the dual function of EphB4 $(10,34,39)$. EphB4 activation leads to cell proliferation and enhanced migration via the phosphoinositide 3-kinase (PI3K)/Akt pathway (40). However, in a mouse xenograft model, EphB4 was demonstrated to inhibit cell growth via the Abl-Crk pathway (10).

EphB6 is an uncommon Eph receptor and lacks catalytic capacity due to its kinase domain changes (41). In an experiment conducted in vitro, reduced EphB6 receptor expression resulted in increased metastatic activity in BC (41). Other studies have demonstrated that EphB6 transcriptional silencing and its consequent effects on the Wnt pathway may contribute to tumor progression in triple-negative BC (42). Additionally, EphB6 receptors with kinase deficiency have been demonstrated to initiate signal transduction from the cell surface to the nucleus, allowing for the expression of a variety of genes alterations that are involved in tumor progression via the PI3K/Akt/mammalian target of rapamycin pathways (43). Furthermore, the interaction of EphB6 with a number of proteins can lead to proteomic profile changes in EphB6-overexpressed MDA-MB-231 cells (44). Significantly 
positive associations have been revealed between EphB6 and $\mathrm{OS}$ in $\mathrm{BC}$ tissue microarrays (37). In the present study, high expression of EphB6 mRNA predicted a longer RFS in all patients with BC. In the subgroup analysis, EphB6 was associated with improved RFS in patients with ER-negative and grade II BC, but was associated with worse RFS in patients with HER2-positive BC, which indicates a dual function of EphB6.

Expression of EphB2 mRNA has been demonstrated to predict poor survival in lymph-node-positive BC (45). Notably, all EphB receptors were associated with worse RFS in patients with lymph-node-positive $\mathrm{BC}$ in the present study.

In addition, we attempted to investigate the prognostic value of the expression of EphB receptors in another independent METABRIC dataset through the cBioPortal for Cancer Genomics (cbioportal.org) $(46,47)$. The genomic profiles of 2,509 patients with $\mathrm{BC}$ were available in the dataset, with data of somatic mutations, copy number alterations and gene expression. However, the detailed clinicopathological features or the best performing thresholds could not be determined using METABRIC. Therefore, important results could have been missed using the cBioPortal; the data have not been presented in the current study.

The functions of ephrin receptors in cancer are paradoxical and complex (48). The ephrin system is essentially present in all types of cancer cell (48). Cancer cellular phenotypes may partly be attributed to a combinatorial expression or interactions of ephrin receptors among the same class, as well as two different classes. For example, EphB6, a receptor with kinase-deficiency, can interact with EphB2 or EphA2 in mammalian cells (49). EphB4 can promote cancer progression independent of EphB6, suggesting that the balance may determine tumorigenesis in the EphB4-EphB6 system (41). Decreased ephrin expression levels have also been associated with tumor progression (50). Consistent with the dichotomy, evidence has demonstrated that ephrin receptors and ephrins exhibit both tumor-promoting and -suppressing activities. For example, in the present study high mRNA expression of EphB3 predicted shorter RFS in ER positive patients but longer RFS in ER-negative patients. Additionally, EphB6 indicated longer RFS in patients with ER-negative BC but a shorter RFS in patients with HER2-positive BC, which suggests the multifaceted roles of these receptors. The underlying mechanisms responsible for these divergent functions have previously been investigated $(7,50,51)$.

The results of the current study are limited for two reasons. First, the database lacks information on clinicopathological features in certain patients, which may lead to statistical bias. Second, multivariate analysis cannot be used in the database to correct the associations between different clinicopathological features. Nevertheless, the comprehensive data suggest that EphB receptors are prognostic factors and traceable targets for $\mathrm{BC}$, which may improve understanding regarding the complexity and heterogeneity of $\mathrm{BC}$ molecular biology. In addition, the current results may assist the development of tools to more accurately predict prognosis and design customized therapies. ELISA can be used as a rapid and sensitive method to detect EphB4 as diagnostic and therapeutic biomarker in BC (45). EphB6 deficiency may be treated by small molecule inhibitors in a synthetic lethality approach (52). Biological products targeting EphB receptors, including antibodies, peptides and recombinant proteins, to reduce the progression of several types of cancer, such as BC, are in the preclinical stages of investigation in animal models. Additionally, at present, certain biopharmaceutical agents are undergoing phase I or phase II clinical trials (e.g., NCT01642342, NCT03552796, NCT02495896) (53-55).

\section{Acknowledgements}

The authors wish to thank Dr Xiaosong Chen (Comprehensive Breast Health Center, Ruijin Hospital, Shanghai Jiaotong University School of Medicine, Shanghai, P.R. China), Dr Jiayi Wu (Comprehensive Breast Health Center, Ruijin Hospital, Shanghai Jiaotong University School of Medicine, Shanghai,P.R. China), Dr Yan Mao Comprehensive Breast Health Center, Ruijin Hospital, Shanghai Jiaotong University School of Medicine, Shanghai, P.R. China), Dr Mingzhu Li (Department of Breast Oncology, The First Hospital of Quanzhou Affiliated to Fujian Medical University, Quanzhou, Fujian, P.R. China), Dr Qinglan Wang (Department of Breast Oncology, The First Hospital of Quanzhou Affiliated to Fujian Medical University, Quanzhou, Fujian, P.R. China) and Dr Chengye Hong (Department of Breast Oncology, The First Hospital of Quanzhou Affiliated to Fujian Medical University, Quanzhou, Fujian, P.R. China) for their kind suggestions regarding this manuscript. In addition, the authors wish to thank Professor Meiyu Geng (Division of Anti-tumor Pharmacology, State Key Laboratory of Drug Research, Shanghai Institute of Materia Medica, Chinese Academy of Sciences, Shanghai, P.R. China), Professor Min Huang (Division of Anti-tumor Pharmacology, State Key Laboratory of Drug Research, Shanghai Institute of Materia Medica, Chinese Academy of Sciences, Shanghai, P.R. China), Professor Hongchun Liu (Division of Anti-tumor Pharmacology, State Key Laboratory of Drug Research, Shanghai Institute of Materia Medica, Chinese Academy of Sciences, Shanghai, P.R. China), Professor Wangmin Qiao (Shenzhen Huada Gene Technology Co., Ltd, Shenzhen, P.R. China) and Professor Ziguan Zhang (Xiamen Zhixin Biotechnology Co., Ltd, Xiamen, P.R. China) for their technical help.

\section{Funding}

Not applicable.

\section{Availability of data and materials}

The datasets used during the current study are available from Kaplan-Meier Plotter (http://kmplot.com).

\section{Authors' contributions}

$\mathrm{XM}, \mathrm{OH}$ and $\mathrm{XZ}$ conceived and designed the study. $\mathrm{XZ}$ and $\mathrm{OH}$ performed the statistical analysis. MJ, ZX and DC analyzed the data. XZ and XM wrote the manuscript.

\section{Ethics approval and consent to participate}

Not applicable. 


\section{Patient consent for publication}

Not applicable.

\section{Competing interests}

The authors declare that they have no competing interests.

\section{References}

1. Siegel RL, Miller KD and Jemal A: Cancer statistics, 2018. CA Cancer J Clin 68: 7-30, 2018

2. Gonzalez-Conchas GA, Rodriguez-Romo L, Hernandez-Barajas D, Gonzalez-Guerrero JF, Rodriguez-Fernandez IA, Verdines-Perez A, Templeton AJ, Ocana A, Seruga B, Tannock IF, et al: Epidermal growth factor receptor overexpression and outcomes in early breast cancer: A systematic review and a meta-analysis. Cancer Treat Rev 62: 1-8, 2018.

3. Pasquale EB: Eph-ephrin bidirectional signaling in physiology and disease. Cell 133: 38-52, 2008.

4. Himanen JP, Saha N and Nikolov DB: Cell-cell signaling via Eph receptors and ephrins. Curr Opin Cell Biol 19: 534-542, 2007.

5. Brantley-Sieders DM: Clinical relevance of Ephs and ephrins in cancer: Lessons from breast, colorectal, and lung cancer profiling. Semin Cell Dev Biol 23: 102-108, 2012.

6. Kaenel P, Mosimann M and Andres AC: The multifaceted roles of Eph/ephrin signaling in breast cancer. Cell Adh Migr 6: 138-147, 2012.

7. Genander M and Frisén J: Ephrins and Eph receptors in stem cells and cancer. Curr Opin Cell Biol 22: 611-616, 2010

8. Lin $\mathrm{B}$, Yin $\mathrm{T}, \mathrm{Wu} \mathrm{YI}$, Inoue $\mathrm{T}$ and Levchenko A: Interplay between chemotaxis and contact inhibition of locomotion determines exploratory cell migration. Nat Commun 6: 6619, 2015.

9. Pasquale EB: Eph receptors and ephrins in cancer: Bidirectional signalling and beyond. Nat Rev Cancer 10: 165-180, 2010.

10. Noren NK, Foos G, Hauser CA and Pasquale EB: The EphB4 receptor suppresses breast cancer cell tumorigenicity through an Abl-Crk pathway. Nat Cell Biol 8: 815-825, 2006.

11. Janes PW, Griesshaber B, Atapattu L, Nievergall E, Hii LL, Mensinga A, Chheang C, Day BW, Boyd AW, Bastiaens PI, et al: Eph receptor function is modulated by heterooligomerization of A and B type Eph receptors. J Cell Biol 195: 1033-1045, 2011.

12. Arvanitis D and Davy A: Eph/ephrin signaling: Networks. Genes Dev 22: 416-429, 2008.

13. Cortina C, Palomo-Ponce S, Iglesias M, Fernández-Masip JL, Vivancos A, Whissell G, Humà M, Peiró N, Gallego L, Jonkheer S, et al: EphB-ephrin-B interactions suppress colorectal cancer progression by compartmentalizing tumor cells. Nat Genet 39: 1376-1383, 2007.

14. Győrffy B, Surowiak P, Budczies J and Lánczky A: Online survival analysis software to assess the prognostic value of biomarkers using transcriptomic data in non-small-cell lung cancer. PLoS One 8: e82241, 2013.

15. Pénzváltó Z, Lánczky A, Lénárt J, Meggyesházi N, Krenács T, Szoboszlai N, Denkert C, Pete I and Győrffy B: MEK1 is associated with carboplatin resistance and is a prognostic biomarker in epithelial ovarian cancer. BMC Cancer 14: 837, 2014.

16. Győrffy B, Bottai G, Lehmann-Che J, Kéri G, Orfi L, Iwamoto T, Desmedt C, Bianchini G, Turner NC, de Thè H, et al: TP53 mutation-correlated genes predict the risk of tumor relapse and identify MPS1 as a potential therapeutic kinase in TP53-mutated breast cancers. Mol Oncol 8: 508-519, 2014

17. Pongor L, Kormos M, Hatzis C, Pusztai L, Szabó A and Győrffy B: A genome-wide approach to link genotype to clinical outcome by utilizing next generation sequencing and gene chip data of 6,697 breast cancer patients. Genome Med 7: 104, 2015.

18. Györffy B, Lanczky A, Eklund AC, Denkert C, Budczies J, Li Q and Szallasi Z: An online survival analysis tool to rapidly assess the effect of 22,277 genes on breast cancer prognosis using microarray data of 1,809 patients. Breast Cancer Res Treat 123: 725-731, 2010

19. Gyorffy B, Lánczky A and Szállási Z: Implementing an online tool for genome-wide validation of survival-associated biomarkers in ovarian-cancer using microarray data from 1287 patients. Endocr Relat Cancer 19: 197-208, 2012.
20. Bonifaci N, Górski B, Masojć B, Wokołorczyk D, Jakubowska A, Dębniak T, Berenguer A, Serra Musach J, Brunet J, Dopazo J, et al: Exploring the link between germline and somatic genetic alterations in breast carcinogenesis. PLoS One 5: e14078, 2010.

21. Becker E, Huynh-Do U, Holland S, Pawson T, Daniel TO and Skolnik EY: Nck-interacting Ste20 kinase couples Eph receptors to c-Jun N-terminal kinase and integrin activation. Mol Cell Biol 20: 1537-1545, 2000.

22. Stein E, Huynh-Do U, Lane AA, Cerretti DP and Daniel TO: Nck recruitment to Eph receptor, EphB1/ELK, couples ligand activation to c-Jun kinase. J Biol Chem 273: 1303-1308, 1998.

23. Vindis C, Cerretti DP, Daniel TO and Huynh-Do U: EphB1 recruits c-Src and p52Shc to activate MAPK/ERK and promote chemotaxis. J Cell Biol 162: 661-671, 2003.

24. Chukkapalli S, Amessou M, Dilly AK, Dekhil H, Zhao J, Liu Q, Bejna A, Thomas RD, Bandyopadhyay S, Bismar TA, et al: Role of the EphB2 receptor in autophagy, apoptosis and invasion in human breast cancer cells. Exp Cell Res 320: 233-246, 2014.

25. Genander M, Halford MM, Xu NJ, Eriksson M, Yu Z, Qiu Z, Martling A, Greicius G, Thakar S, Catchpole T, et al: Dissociation of EphB2 signaling pathways mediating progenitor cell proliferation and tumor suppression. Cell 139: 679-692, 2009.

26. Husa AM, Magić Z, Larsson M, Fornander T and Pérez-Tenorio G: EPH/ephrin profile and EPHB2 expression predicts patient survival in breast cancer. Oncotarget 7: 21362-21380, 2016.

27. Lam S, Wiercinska E, Teunisse AF, Lodder K, ten Dijke P and Jochemsen AG: Wild-type p53 inhibits pro-invasive properties of TGF- $\beta 3$ in breast cancer, in part through regulation of EPHB2, a new TGF- $\beta$ target gene. Breast Cancer Res Treat 148: 7-18, 2014.

28. Poliakov A, Cotrina ML, Pasini A and Wilkinson DG: Regulation of EphB2 activation and cell repulsion by feedback control of the MAPK pathway. J Cell Biol 183: 933-947, 2008.

29. Dail M, Richter M, Godement P and Pasquale EB: Eph receptors inactivate R-Ras through different mechanisms to achieve cell repulsion. J Cell Sci 119: 1244-1254, 2006.

30. Miao H, Strebhardt K, Pasquale EB, Shen TL, Guan JL and Wang B: Inhibition of integrin-mediated cell adhesion but not directional cell migration requires catalytic activity of EphB3 receptor tyrosine kinase. Role of Rho family small GTPases. J Biol Chem 280: 923-932, 2005.

31. Maddigan A, Truitt L, Arsenault R, Freywald T, Allonby O, Dean J, Narendran A, Xiang J, Weng A, Napper S and Freywald A: EphB receptors trigger Akt activation and suppress Fas receptor-induced apoptosis in malignant $\mathrm{T}$ lymphocytes. J Immunol 187: 5983-5994, 2011.

32. Nikolova Z, Djonov V, Zuercher G, Andres AC and Ziemiecki A: Cell-type specific and estrogen dependent expression of the receptor tyrosine kinase EphB4 and its ligand ephrin-B2 during mammary gland morphogenesis. J Cell Sci 111: 2741-2751, 1998.

33. Munarini N, Jäger R, Abderhalden S, Zuercher G, Rohrbach V, Loercher S, Pfanner-Meyer B, Andres AC and Ziemiecki A: Altered mammary epithelial development, pattern formation and involution in transgenic mice expressing the EphB4 receptor tyrosine kinase. J Cell Sci 115: 25-37, 2002.

34. Rutkowski R, Mertens-Walker I, Lisle JE, Herington AC and Stephenson SA: Evidence for a dual function of EphB4 as tumor promoter and suppressor regulated by the absence or presence of the ephrin-B2 ligand. Int J Cancer 131: E614-E624, 2012.

35. Pradeep S, Huang J, Mora EM, Nick AM, Cho MS, Wu SY, Noh K, Pecot CV, Rupaimoole R, Stein MA, et al: Erythropoietin stimulates tumor growth via EphB4. Cancer Cell 28: 610-622, 2015.

36. Li X, Song C, Huang G, Sun S, Qiao J, Zhao J, Zhao Z and Li M: The coexpression of EphB4 and EphrinB2 is associated with poor prognosis in HER2-positive breast cancer. Onco Targets Ther 10: 1735-1742, 2017

37. Brantley-Sieders DM, Jiang A, Sarma K, Badu-Nkansah A, Walter DL, Shyr Y and Chen J: Eph/ephrin profiling in human breast cancer reveals significant associations between expression level and clinical outcome. PLoS One 6: e24426, 2011.

38. Barneh F, Moshayedi M, Mirmohammadsadeghi H Haghjooy-Javanmard S, Sabzghabaee AM and Badri S: EphB4 tyrosine kinase stimulation inhibits growth of MDA-MB-231 breast cancer cells in a dose and time dependent manner. Dis Markers 35: 933-938, 2013.

39. Noren NK and Pasquale EB: Paradoxes of the EphB4 receptor in cancer. Cancer Res 67: 3994-3997, 2007.

40. Steinle JJ, Meininger CJ, Forough R, Wu G, Wu MH and Granger HJ: Eph B4 receptor signaling mediates endothelial cell migration and proliferation via the phosphatidylinositol 3-kinase pathway. J Biol Chem 277: 43830-43835, 2002. 
41. Truitt L, Freywald T, DeCoteau J, Sharfe N and Freywald A: The EphB6 receptor cooperates with c-Cbl to regulate the behavior of breast cancer cells. Cancer Res 70: 1141-1153, 2010.

42. Bhushan L, Tavitian N, Dey D, Tumur Z, Parsa C and Kandpal RP: Modulation of liver-intestine cadherin (Cadherin 17) expression, ERK phosphorylation and WNT signaling in EPHB6 receptor-expressing MDA-MB-231 cells. Cancer Genomics Proteomics 11: 239-249, 2014

43. Fox BP and Kandpal RP: EphB6 receptor significantly alters invasiveness and other phenotypic characteristics of human breast carcinoma cells. Oncogene 28: 1706-1713, 2009.

44. Kandpal RP: Tyrosine kinase-deficient EphB6 receptor-dependent alterations in proteomic profiles of invasive breast carcinoma cells as determined by difference gel electrophoresis. Cancer Genomics Proteomics 7: 253-260, 2010.

45. Moshayedi M, Barneh F, Haghjooy-Javanmard S, Sadeghi HM Eskandari N and Sabzghabaee AM: A rapid and sensitive method for EphB4 identification as a diagnostic and therapeutic biomarker in invasive breast cancer. J Cancer Res Ther 12: 188-192, 2016

46. Curtis C, Shah SP, Chin SF, Turashvili G, Rueda OM Dunning MJ, Speed D, Lynch AG, Samarajiwa S, Yuan Y, et al: The genomic and transcriptomic architecture of 2,000 breast tumours reveals novel subgroups. Nature 486: 346-352, 2012.

47. Pereira B, Chin SF, Rueda OM, Vollan HK, Provenzano E, Bardwell HA, Pugh M, Jones L, Russell R, Sammut S, et al: The somatic mutation profiles of 2,433 breast cancers refines their genomic and transcriptomic landscapes. Nat Commun 7: 11479, 2016.

48. Kullander K and Klein R: Mechanisms and functions of Eph and ephrin signalling. Nat Rev Mol Cell Biol 3: 475-486, 2002.
49. Fox BP and Kandpal RP: A paradigm shift in EPH receptor interaction: Biological relevance of EPHB6 interaction with EPHA2 and EPHB2 in breast carcinoma cell lines. Cancer Genomics Proteomics 8: 185-193, 2011.

50. Klein R: Bidirectional modulation of synaptic functions by Eph/ephrin signaling. Nat Neurosci 12: 15-20, 2009.

51. Orsulic S and Kemler R: Expression of Eph receptors and ephrins is differentially regulated by E-cadherin. J Cell Sci 113: 1793-1802, 2000.

52. Paul JM, Toosi B, Vizeacoumar FS, Bhanumathy KK, Li Y, Gerger C, El Zawily A, Freywald T, Anderson DH, Mousseau D, et al: Targeting synthetic lethality between the SRC kinase and the EPHB6 receptor may benefit cancer treatment. Oncotarget 7: 50027-50042, 2016.

53. Lodola A, Giorgio C, Incerti M, Zanotti I and Tognolini M: Targeting Eph/ephrin system in cancer therapy. Eur J Med Chem 142: 152-162, 2017.

54. Chrencik JE, Brooun A, Recht MI, Nicola G, Davis LK, Abagyan R, Widmer H, Pasquale EB and Kuhn P: Three-dimensional structure of the EphB2 receptor in complex with an antagonistic peptide reveals a novel mode of inhibition. J Biol Chem 282: 36505-36513, 2007.

55. Koolpe M, Burgess R, Dail M and Pasquale EB: EphB receptor-binding peptides identified by phage display enable design of an antagonist with ephrin-like affinity. J Biol Chem 280: $17301-17311,2005$

This work is licensed under a Creative Commons Attribution-NonCommercial-NoDerivatives 4.0 International (CC BY-NC-ND 4.0) License. 